\title{
Climate Resilient Plant for Seed Spices
}

\author{
Divakara Sastry EV \\ Department of Genetics and Plant Breeding, Central Agricultural University, India
}

Submission: February 02, 2017; Published: April 26, 2017

"Corresponding author: Divakara Sastry EV, Department of Genetics and Plant Breeding, College of Agriculture, Central Agricultural University, Imphal 795004, India, email: evdsastry@gmail.com

\section{Introduction}

We have seen the wrath of nature. This year the onset of winter was considerably delayed and as a result, because of changed weather, the rabi crops suffered a lot. An estimate puts the agricultural output in our country during the current Rabi is going to be $20 \%$ less. Imagine the impact that it is going to be having on the food prices. Spices are no exception. Although lack of frost should be boon to spices production, as we can expect less disease incidence but reduced cool period may affect the quality. Quality which is judged by aroma due to essential oils present in seed spices. The weather has been most unfavorable to cumin for the last three years. If the season continues as it is, then we can expect a very good crop of cumin. Unfortunately we can't rely on the weather. It can change any time and as our past experience indicates, most damage is caused towards the end of the season when the grain formation is either going on or crop has almost matured, when unseasonal rains have created havoc to the extent that in some cases a hundred percent washout was noted. Over the years the climate has become more unpredictable, with the global warming increasing day by day, climatologists are puzzled as they are and warn of bitter times ahead. Climate change is the most important global environmental challenge facing humanity with implications for natural ecosystems, agriculture and health $[1,2]$. The perusal of general circulation models (GCMs) on climate change indicate that rising levels of greenhouse gases (GHGs) are likely to increase the global average surface temperature by $1.5-4.5{ }^{\circ} \mathrm{C}$ over the next 100 years. The difference of average temperature between the last ice age and present climate is $6^{\circ} \mathrm{C}$. This will raise sea-levels, shift climate zones pole ward, decrease soil moisture and storms. Global warming is predicted to affect agricultural production [3]. This is time we need to put our efforts together to fight; at least change the way the agriculture is happening. New climate resilient plants need to be bred. By 2050 global demand for food is going to be doubled because of the increase in population, consumption and because of the quality of life [4,5]. With the increase in quality of life the demand is going to be even more in spices, as spices add flavour and quality to the food. All this demand is to be met from the existing land resources only, with no increase in arable land, avoiding environmental degradation, maintaining the ecosystems as they are and also preventing biodiversity [6]. Spices will get even less land, as the demand for land by the major food crops particularly cereals over weigh against the spices, this is particularly true for seed spices which as such are grown on less favored lands. Even in the major crops, which had the greater attention in terms of breeding efforts and improvement, stagnation in crop yield growth rates in various regions around the world have become common place such as in rice $[7,8]$. Wheat and partly attributed to changes in agronomic management and climatic conditions As well as due to increasing water scarcities, and nutrient status of the soil [9]. All this prompts to rethink on how to breed better yielding genotypes for sustained production/productivity in a myriad of forces which limit the crop production. With information on the genetics becoming available and with the molecular genetics playing a greater role in crop improvement. It is imperative that an ideal plant type is designed to assist the breeder to breed high yielding and adaptive genotypes for various cultivation requirements.

\section{Effect of Climate Change on Agriculture}

Climate is changing naturally at its own pace, since the beginning of the evolution of earth, 4-5 billion years ago, but presently, it has gained momentum due to inadvertent anthropogenic disturbances. These changes may culminate in adverse impact on human health and the biosphere on which we depend. The multi-faceted interactions among the humans, microbes and the rest of the biosphere, have started reflecting an increase in the concentration of greenhouse gases (GHGs) i.e. $\mathrm{CO}_{2} \mathrm{CH}_{4}$ and $\mathrm{N}_{2} \mathrm{O}$, causing warming across the globe along with other cascading consequences in the form of shift in rainfall pattern, melting of ice, rise in sea level etc. The above multifarious interactions among atmospheric composition, 
climate change and human, plant and animal health need to be scrutinized and probable solutions to the undesirable changes may be sought [10].

The rise in temperature due to emission of greenhouse gases into the atmosphere has a profound effect on the Earth's climate system as a whole, and this in turn has important consequences for the geosphere and biosphere. The authoritative source for information regarding such effects remains the periodic assessment reports of the Intergovernmental Panel on Climate Change (IPCC), the latest being the Fourth Assessment Report (AR4) released in 2008. The Fifth Assessment Report is currently under preparation and is due in 2012. According to AR4,

The most significant climatic changes that could result from global warming are as follows (Jayaraman, n.d.):

a. Daily and seasonal temperature patterns could change with increases in both maximum and minimum temperatures. Temperature increases will be the greatest over land in the northern latitudes, with fewer cold days and nights and an increasing number of hot days and nights.

b. Rainfall patterns could be subject to significant changes, with subtropical regions of the world likely to receive significantly lower rainfall and the northern latitudes experiencing increased rainfall. It is not only the total annual or seasonal rainfall that may change, but also the distribution of rainfall within a year or season. Consequently, the same total precipitation in a rainy season could be delivered over a fewer number of rainy days.

c. Rising temperatures will lead to increased frequency of extreme weather events like heat waves, extremely heavy rainfall, and intense storms and cyclones. Seasonal climate patterns, such as the monsoon, could also undergo changes.

d. Following the increase in global temperatures, the melting of polar ice-caps will contribute to a rise in sea levels, although there are uncertainties regarding the extent of the rise. Rising sea levels will pose a threat of submergence to coastal communities and many island nations.

e. Global warming will lead to changes in the oceans. Due to increased $\mathrm{CO}_{2}$ concentration the oceans will acidify, resulting in adverse consequences for marine flora and fauna. Ocean temperatures will also be affected, and disturbances in the current pattern of flow of ocean currents are possible. The flow pattern of ocean currents is an integral part of the mechanism by which the heat balance of the Earth is maintained. While disturbances in this pattern may be small in the present century, their impact on ocean circulation in later periods is less certain. The Climate change therefore affects agriculture in several ways which is summarized graphically in (Figure 1).

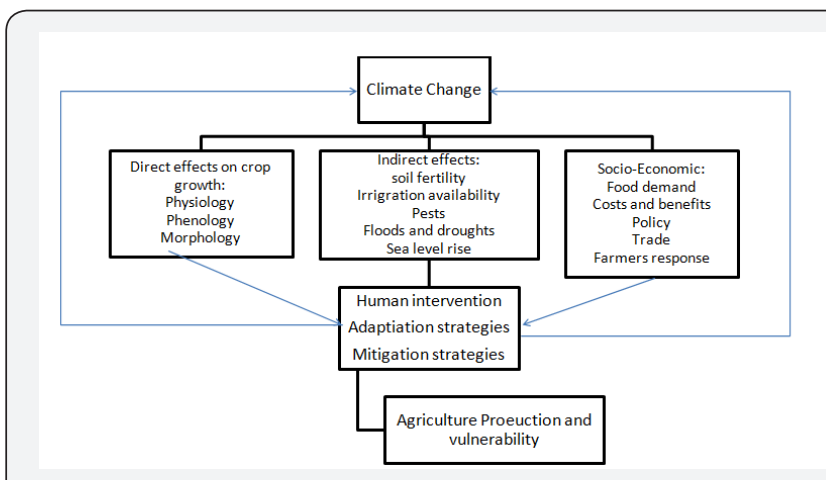

Figure 1: Assessment of vulnerability of Agriculture to Climate Change.

Some predict positive impacts on agriculture from climate change like increased temperatures and higher carbon dioxide levels [11]. Increased concentrations of $\mathrm{CO}_{2}$ may boost crop productivity, only where moisture is not a constraint. Higher levels of $\mathrm{CO}_{2}$ can stimulate photosynthesis in certain plants (30100 per cent). Experimental observations confirm that when plants absorb more carbon grow bigger and more quickly. This is particularly true for C3 plants (so called because the product of their first biochemical reactions during photosynthesis has three carbon atoms). Increased $\mathrm{CO} 2$ tends to suppress photorespiration in these plants, making them more water-efficient. The response of $\mathrm{C} 4$ plants would not be as dramatic. C3 plants correspond to mid-latitude food staples like wheat, rice and soy bean whereas C4 plants correspond to low-altitude crops like maize, sorghum \& sugarcane. The impact on yields of lowlatitude crops is more difficult to predict while the mid-latitude yields may be reduced by 10-30 per cent due to increased summer dryness [3].

\section{Designing a Plant Type or Ideotype}

I wish to quote few lines from "When a new variety is produced in this way, the plant breeder may not know why it yields better than its predecessors [12]. A wheat breeder, who recently produced a high yielding variety of wheat, was asked what attributes gave it such capacity for yield; he replied, "I do not know... but I will list the characteristics of the variety, and it is for the physiologist to judge whether these may be the reasons for the high yield." Many cereal breeders selecting for yield give a like reply, or state that the new variety has "better adaptation" to the environment". Unfortunately these lines appear to be true still and particularly in seed spices. Breeding efforts can be categorized into two groups- "defect elimination" which basically mean removing any kind of defects in the plants to make them more productive, like breeding for disease resistance and the second group "selection for yield", which basically mean breeding cultivars which have higher yield than their competitors. In seed spices the "defect elimination" is still in infancy while almost all the efforts are directed towards "selection for yield". This is time 
we think of modifying our efforts.

The term Ideotype as introduced by Donald [12] basically refers to a biological model which is expected to perform or behave in a predictable manner within a defined environment. In other words, it refers to a model plant or ideal plant type that the breeder will make efforts to achieve. Naturally this will depend on different components inherent to the plant. All the plant types that we see today are specific Ideotype that nature has modeled for different ecological niches. So that all the species are adjusted in the limited space and there is less competition for space and resources. However when it comes to cultivated crops, the needs become different hence it becomes essential a different Ideotype. The possible types of Ideotype are listed in Figure 2. Out of the listed types of Ideotype, our interest is in designing a plant type that counters the changing weather pattern.

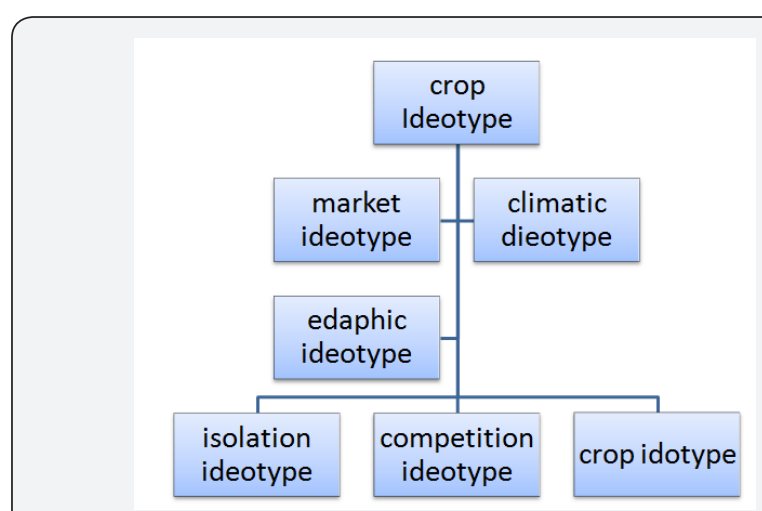

Figure 2: Possible types of Ideotype. Our interest at present is in edaphic Ideotype which helps us design a plant based on tolerating environment (Based on Sastry, 2015)

Development of Ideotype is a conceptual one and requires inputs from all the stake holders. A good Ideotype is based on interdisciplinary approach and is a continuously evolving process with new inputs integrating into the Ideotype concept. Donald [12] proposed the Ideotype approach to plant breeding in contrast to the empirical breeding approach of defect elimination and selection for yield per se. He defined "crop Ideotype" as an idealized plant type with a specific combination of characteristics favorable for photosynthesis, growth, and grain production based on knowledge of plant and crop physiology and morphology. Thus according to him, an Ideotype is a biological model that is expected to perform or behave in a predictable manner within a defined environment, emphasizing on the importance of understanding both the genotype performance and the environments to define the relevance of a specific combination of traits. He argued that it would be more efficient to define a plant type that was theoretically efficient and then breed for this [13]. Recently Matr et al. [14] extended this definition suggesting that the Ideotype is a combination of different types of traits (morphological, physiological) or its genetic basis that confer enhanced performance for a particular
I. biophysical environment,

II. specific cropping system and

III. End use of the crop.

Crop simulation models have been applied in various ways to support plant breeding, e.g. to design crop Ideotype for different environments aimed at minimizing resource use per unit of dry matter produced and to increase crop yield potential $[15,16]$. Particularly promising has been the application of crop simulation to estimate yield potential in crop Ideotype designed for projected future climates. For example, applied wheat simulation model Sirius across Europe to optimize wheat Ideotype for future climate scenarios, whereby a wheatideotype was defined as a set of selected cultivar parameters related to photosynthesis, phenology, crop canopy characteristics, and water relations. By changing parameters from given value ranges and optimizing them for yield in response to changing climate or environmental conditions, Ideotype were defined that showed best yield performance under well-defined future conditions.

\section{Ideotype for Spices}

Possible Ideotype for seed spices is given below based on the available information. Coriander- coriander is used both as herb (for leaves) as well as for seed. The seeds as well as plant parts contain essential oil which actually imparts the typical flavor to the coriander. The chemical composition of the essential oil is described by Parthsarathy [17]. The general cultivation method includes sowing of seeds by broadcasting either in raised beds or in flat beds and harvesting the leaves either by cutting at an interval of 25 to 30 days (generally two cuttings are taken) or by uprooting the plants at 25-30 days when sown for leaves and broad casting or line sowing when the crop is intended for seeds. A good description about the cultivation method is given by Sastry et al. [18]. A good account of the plant type is given by Diederichsen \& Sastry [19,20]. Distinct changes are seen in plant type during the life cycle of the plant. Based on the differences in the plant shape, three types are recognizedprostrate (spreading), semi erect and erect. The spreading types are better suited for leaf purposes as their biomass is more and they rapidly grow. But when one is interested in seed types, the erect plant is found to be better suited. For the development of the Ideotype, it is essential to understand the morphological characters vis-à-vis their relation with the final character the seed yield. Unfortunately as of now the genetics of morphological traits that affect the seed yield in coriander is still not know although, correlation and path analysis have thrown some light [21-23]. Most of the morphological traits show high genetic diversity and are positively correlated with seed yield. Most important, there is positive correlation of seed yield with the days to flowering and maturity [24]. Or the correlations are very weak with high positive direct effect [25]. This needs some relook. In order to further understand, a detailed study of the 
different types of flowering characters and morphological traits as well as seed yield was studied with a view to understand the flowering behavior and morphological traits which impact yield. The multivariate analysis based on principal component analysis of all the genotypes indicated wide variation among the genotypes. Further analysis of the characters has indicated two distinct groups of characters- those related to flowering and morphological characters. This indicates importance of the flowering duration in the seed yield. Further, when the genotypes were categorized based on the seed yield, the top yielding genotypes were in general long duration varieties, while the low yielding genotypes were generally early to flower and to mature. Further an initial study on the number of leaf cuttings vs. seed yield of selected genotypes at S K N Agriculture University has shown that seed yield of the genotypes which have given two cuttings of leaves was generally lower. These findings support the view that the genotypes for leaf yield should be distinct from the types which are bred specifically for the seed yield. The erect types are better suited for the seed yield. Observations from the correlations study indicate that it is ideal to have genotypes which start flowering earlier and also have long grain filling period. However, with the climate change as it is happening, towards the maturity, coriander is exposed to sudden rises in the temperatures in North India. Under such conditions, having long duration plant types will be detrimental. As such a positive correlation between seed yield and flowering is seen. So in order to breed climate resilient genotypes, this positive correlation will have to be broken. Mutation breeding may become the method dè desire. These are preliminary observations and knowledge of physiological parameters will be needed before a logical Ideotype is designed.

Fennel- Fennel is long duration crop with indeterminate flowering behavior. The plant is generally tall. As of now very little information is available which may be used for designing an Ideotype. As such the plant types can be classified into short and tall types. The fennel is cultivated by two methods- direct sowing and transplanted. The transplanted types require long duration (>10 months) while the direct sowing is raised as Rabi crop required around $6 \frac{1}{2}$ months. The heights of the plants reach $2 \mathrm{~m}$. for good quality product, multiple pickings are practiced. This is particularly required when the harvesting is done for green fennel which has good flavor and fetches more prices. Again, a positive correlation between major morphological traits and seed yield is reported in fennel [26]. While very low non-significant correlation has been reported between days to flowering and seed yield [27]. Hence, genotypes with late flowering habitat are high yielding. Therefore the Ideotype for high yielding varieties should incorporate shorter height, start flowering earlier and as far as possible should be synchronous in maturity. Such genotypes are expected to yield high in short duration. Even the foliage is profuse and drooping. Fennel is intercropped with several other crops. Therefore compact plant type is a preferred
Ideotype for fennel when used in intercropping. As of now genotypes which are shorter and showing synchrony in maturity are not found in fennel. Once again mutation breeding may come to rescue to develop unique plant type. At NRCSS, Ajmer, mutants which are very short have been identified although the stability of their performance is yet to be studied.

Fenugreek- Fenugreek plant has a slender stem owing to which the plants prostrate. Because of the prostrate habit, plants get entangled and become vulnerable to soil born fungi. Moreover, the pods appear along the stem because of which non synchronous maturity is observed. This also makes machine harvesting difficult and the realized yields are low. Fortunately we have determinate plant type (UM 305) available. This genotype is short and the pods point upwards which makes high density sowings possible. This plant type may be used as a model Ideotype to breed high yielding varieties in fenugreek. Fenugreek is plagued by powdery mildew and downy mildew is becoming problems.

Cumin- The plants of cumin are slender and short with near synchronous flowering and maturity making the plant types an ideal plant. The biggest challenge in cumin is its susceptibility to biotic stresses namely wilt and blight. As of now no resistance source is available against both the diseases. Hence intense search for resistant source is required. Search for somaclonal variants using in vitro techniques have been done [28] but with limited success.

\section{Prologue}

In seed spices, in order to develop Ideotype basic genetic information is still not available. Even the physiological and biochemical traits which affect the yield and the quality of spices i.e. essential content in case of coriander, fennel and cumin and dysgenic content in fenugreek are still not worked out. With the available information, breeding for synchrony in flowering and maturity, erect type with higher sink size in relation to source is needed so that optimum yields are obtained under irrigated conditions. With the availability of information on the genetics of major morphological traits, and the effect of changing climate, we may develop Ideotype for different situation enumerated at the beginning of this manuscript. With the availability of information one may develop Ideotype for a given situation as proposed by Rotter [29] even through simulation can be generated [30-32].

\section{References}

1. Parikh JK, Parikh K (2002) Climate change: India's perceptions, postions and possibilities, Paris: OECD.

2. Senapati MR (2009) Vulnerabilities to climate change', Kurukshetra. American Journal of Environmental Protection 1(4): 109-111.

3. Senapati MR, Behera B, Mishra SR (2013) Impact of climate change on Indian agriculture and its mitigating priorities', American Journal of environmental protection, 1(4): 109-111. 
4. Kastner T, Rivas MJI, Koch W, Nonhebel S (2012) Global changes in diests and the consquences for land requirement for food. Proceedings of the National Academy of Sciences 109(18): 6868-6972.

5. Tillman D, Balzer C, Hill J, Berfort BL (2011) Global food demand and the sustainable intensification of agriculture. Proceedings of National Academy of Sciences 108(50): 20260-20264.

6. Cassman KG (1999) Ecological intensification of cereal production systems: yield potential, soil quality and precision agriculture. Proceedings of National Academy of Sciences 96(11): 5952-5959.

7. Lobel DB, Gourdji SM (2012) The influence of climate change on global crop productivity. Plant Physiology 160(40): 1686-1697.

8. Ray DK, Ramankutty N, Mueller ND, West PC, Foley JA, et al. (2012) Recent patterns of crop yield growth and stagnation. Nature Communications 3: 1293.

9. Carbewrry PS, Liang W, Twomlow S, Holzworth DP, Dimes JP, et al. (2013) Scope for improved eco-efficiency varies among diverse cropping systems. Proceedings of National Academy of Sciences 110(21): 8381-8386.

10. Khan SA, Kumar S, Hussain MZ, Kalra N (2009) Climate Change, Climate variability and Indian Agriculture: Impacts Ulnerability and adaptation Stategies in SN S (eds.), Climate Change and crops, Heidelberg: Springer-Verlag.

11. Mendelssohn, R, William DN, Daigee Shaw (1994) The Impact of Global Warming on Agriculture: A Ricardian Analysis. American economic review 84(4): 753-771.

12. Donald CM (1968) the breeding of crop ideotypes. Euphytica 17: 385403.

13. Hamblin J (1993) The Ideotype concept: useful or outdated. International crop Science I, Crop Science Society of America, Madison, USA pp. 589-597.

14. Matr P, Quilot-Turion, Luquet B, Ould-Sidi MD, Chenu MM, et al. (2015) Model assisted phenotyping and ideotype design. crop Physiology, pp. 349-373.

15. Aggarwal PK, Kropff MJ, Teng PS , Khush GS (1997) The challenge of integrating systems approaches in plant breeding: opportunities, accomplishments and limitations. Application of systems approaches at the field level 6: 1-23.

16. Dingkuhn M, Penning de Vries FWT, Datta SK, van Laar HH (1991) Concepts for a new plant type for direct seeded flooded tropical rice. in Selected Papers from the International Rice Research Conference Seoul. Korea, Mani: International Rice Research Institute pp. 27-31.

17. Parthsarathy VA, John Zachariah T, Champakarm B (2008) Coriander in Chemistry of Spices. Allingford, Oxfordshire: CABI.

18. Sastry VD, Singh D, Shekhawat KS, Jat NL, Rajput SS, et al. (2009) Seed spices in Rajasthan and their improvement, Jobner: S K N College of
Agriculture.

19. Diederichsen A (1996) Coriander Rome. International Plant Genetic Resources Institute pp.83.

20. Sastry EVD, Singh D, Rajput SS, Ravindrababu Y, Jaiman RK, et al. (2011) Status of Charecterization and evaluation in coriander. in Recent Advances in Seed Spices, New Delhi: Daya Publishing House.

21. Arif M, Khushid H, Khan SA (2014) Genetic structure and green leaf performance evalaution of geographically diverse populations of coriander (Coriandrum sativum L.). European Academic Research 2(3): 3269-3285.

22. Dyulgerov N, Dyulgerov B (2013) Variation of yield components in coriander (Coriandrum sativum L.). Agricultural Science and technology 5(2): 160-163.

23. Meena YK, Kale VS, Meena OP (2014) Correlation coefficient and path analysis in coriander.International journal of scientific and research publications, 4(6): 1-4.

24. Pandey $Y$ (2013) Evaluation of coriander germplasm for yield and yield attributes. M Sc (Ag) thesis, Campus Jobner: S K Rajasthan Agricultural University.

25. Idhol BD, Desai RT, Khandelwal V, Godke UR (2011) Genetic variability, correlation coefficient and path analysis studies in coriander (Coriandrum sativum L.). aromatic plants- Status and improvement, Jaipur: Pointer Publishers.

26. Yadav PS, Pandey VP, Yadav Y (2013) Variability studies in fennel (Foeniculum vulgare Mill.). Journal of spices and aromatic crops 22(2): 203-208.

27. Singh VV (2003) Comparative study of full sib half sibn and selfed progenies in two diverse populations of fennel (Foeniculum vulgare Mill). Journal of Spices and Aromatic Crops 13(2): 129-131.

28. Jakhar ML, Sastry EVD, Dhayal LS, Rathore VS (2003) Callusing response of hypocotyl, shoot apical and leaf explants of cumin (Cuminum cyminum L.) to plant growth regulator treatments. Indian Journal of Plant Physiology (Special Issue): 685-688.

29. Rotter RP, Tao F, Hohn JG, Palosuo T (2015) Use of crop simulation modeklling to aid ideotype design of future cereal cultivars. J Exp Bot 66(12): 3463-3476.

30. Jayaraman T (2011) Climate Change and Agriculture: A review article with special reference to Indian. Review of Agrarian Studies 1(2): 1675.

31. Sastry EVD, Singh D, Rajput SS (2011) Spices and aromatic plantsstatus and improvement. Pointer Publisherrs, India, p. 252.

32. Trnka M, Rotter RP, Rulz-Ramos M, Kersebaum KC, Olesen JE, et al. (2014) Adverse weather conditions for European wheat production will become more frequent with climate change. Nature Climate Change 4: 637-643. 
This work is licensed under Creative Commons Attribution 4.0 License DOI: $10.19080 /$ CTBEB.2017.03.555613

\section{Your next submission with Juniper Publishers} will reach you the below assets

- Quality Editorial service

- Swift Peer Review

- Reprints availability

- E-prints Service

- Manuscript Podcast for convenient understanding

- Global attainment for your research

- Manuscript accessibility in different formats ( Pdf, E-pub, Full Text, Audio)

- Unceasing customer service

Track the below URL for one-step submission https://juniperpublishers.com/online-submission.php 